\title{
OxLDL promotes lymphangiogenesis and lymphatic metastasis in gastric cancer by upregulating VEGF-C expression and secretion
}

\author{
CAIQI MA ${ }^{1 *}$, JINYE XIE $^{2 *}$, CHUANGHUA LUO ${ }^{2 *}$, HAOFAN YIN $^{2}$, RUOPU LI $^{2}$, XI WANG $^{2}$, \\ WENJUN XIONG ${ }^{3}$, TING ZHANG ${ }^{4}$, PING JIANG ${ }^{2}$, WEIWEI QI ${ }^{2}$, TI ZHOU ${ }^{2}$, ZHONGHAN YANG ${ }^{2}$, \\ WEI WANG ${ }^{3}$, JIANXING MA ${ }^{5}$, GUOQUAN GAO ${ }^{1,2,6}$ and XIA YANG ${ }^{1,2,7}$ \\ ${ }^{1}$ Department of Internal Medicine, Affiliated Guangzhou Women and Children's Medical Center; \\ ${ }^{2}$ Department of Biochemistry, Zhongshan School of Medicine, Sun Yat-sen University, Guangzhou, \\ Guangdong 510080; ${ }^{3}$ Department of Gastrointestinal Surgery, Traditional Chinese Medicine Hospital \\ of Guangdong Province, Guangzhou, Guangdong 510080; ${ }^{4}$ Department of Laboratory Medicine, \\ The Second Affiliated Hospital of South China University of Technology, Guangzhou, Guangdong 510080, \\ P.R. China; ${ }^{5}$ Department of Physiology, University of Oklahoma, Health Sciences Center, Oklahoma City, \\ OK 73104, USA; ${ }^{6}$ China Key Laboratory of Tropical Disease Control, Sun Yat-sen University, \\ Ministry of Education; ${ }^{7}$ Guangdong Engineering and Technology Research Center for Gene Manipulation \\ and Biomacromolecular Products, Sun Yat-sen University, Guangzhou, Guangdong 510080, P.R. China
}

Received May 16, 2018; Accepted October 10, 2018

DOI: 10.3892/ijo.2018.4648

\begin{abstract}
Gastric cancer is one of the most malignant tumor types, and its metastasis is a notable cause of mortality. Among the methods of tumor metastasis, lymphatic metastasis is the predominant one in gastric cancer. A previous study reported that the plasma oxidized low-density lipoprotein (oxLDL) is the risk factor associated with the development of tumors in patients with abnormal lipid metabolism, but the influence of plasma oxLDL in the lymphatic metastasis of gastric cancer remains unclear. In the present study, the concentration of plasma oxLDL from patients with gastric cancer was detected with an ELISA kit, and the lymphatic vessel density in gastric cancer tissues was determined by D2-40 staining. The correlation analysis of oxLDL concentration and lymphatic vessel density demonstrated that plasma oxLDL was positively
\end{abstract}

Correspondence to: Professor Xia Yang or Professor Guoquan Gao, Department of Biochemistry, Zhongshan School of Medicine, Sun Yat-sen University, 74 Zhongshan 2nd Road, Guangzhou, Guangdong 510080, P.R. China

E-mail: yangxia@mail.sysu.edu.cn

E-mail: gaogq@mail.sysu.edu.cn

${ }^{*}$ Contributed equally

Key words: oxidized low-density lipoprotein, lymphangiogenesis, lectin-like oxidized low-density lipoprotein receptor, nuclear factor- $\kappa \mathrm{B}$, vascular endothelia growth factor- $\mathrm{C}$, lymph node metastasis, gastric cancer correlated with lymphatic metastasis in patients with gastric cancer. Subsequently, the popliteal lymph node metastasis animal experiment with nude mice confirmed that oxLDL could promote the lymphatic metastasis of gastric cancer. Following this, the western blotting and ELISA data demonstrated that oxLDL promoted the expression and secretion of vascular endothelia growth factor (VEGF)-C in gastric cancer cell lines. Finally, blocking the lectin-like oxLDL-1 (LOX-1) receptor, a specific receptor for oxLDL, and the nuclear factor (NF) $-\kappa \mathrm{B}$ signaling pathway following oxLDL $(50 \mu \mathrm{g} / \mathrm{ml})$ treatment in $\mathrm{HGC}-27$ cells revealed that oxLDL could activate the $\mathrm{NF}-\kappa \mathrm{B}$ signaling pathway mediated by LOX-1, with subsequent upregulation of VEGF-C expression, and secretion in and from gastric cancer cells, and finally that it could promote the lymphatic metastasis of gastric cancer. These data indicate the association between the plasma oxLDL and the lymphatic metastasis of gastric cancer, and indicate that oxLDL elimination may be a potential therapeutic target for the prevention and intervention of early lymph node metastasis in gastric cancer.

\section{Introduction}

Gastric cancer is one of the dangerous malignant tumor types, due to its threat to the health of people globally, with it being the second most common cancer type and a leading cause of mortality in China in 2015 (1). A significant decline in incidence has occurred since 20th century due to the efficient prevention and treatment of $H$. pylori infection, which commonly results in non-cardia gastric cancer; however, the morbidity of cardia gastric cancer is rising in Europe and North America in 2012, due to the increasingly high-fat 
diets $(2,3)$. No significant improvements have been produced in advancing the diagnosis and treatment of gastric cancer, and it frequently metastasizes prior to identification (4). In a number of metastatic models of gastric cancer, lymph node metastasis is not only a major type of metastasis but also the early route $(4,5)$. Additionally, gastric cancer with lymphatic metastasis will be refractory, due to the difficulties in full elimination with surgical resection or chemoradiotherapy (6). Therefore, it is of vital importance to develop novel therapies for the early intervention of lymph node metastasis in gastric cancer.

Obesity is a well-recognized risk factor for gastric cancer in the USA and China $(7,8)$. However, it remains controversial whether the body mass index (BMI), which is currently the standard measure of obesity, has a positive association with the incidence and mortality of gastric cancer $(9,10)$. A recent review reported that BMI was predominantly an indicator for cardia gastric cancer, rather than non-cardia (9); additionally, a meta-analysis indicated high fat-intake was positively associated with gastric cancer incidence (10). Furthermore, increasing evidence indicates that hyperlipidemia is positively associated with lymphatic metastasis in a number of cancer types, including esophageal and gastric cancer $(11,12)$. Thus, it is indicated that abnormal lipid level may have a negative effect on patients with gastric cancer through promoting lymphatic metastasis. Nevertheless, it remains unclear which variety of dyslipidemia stimulates gastric cancer lymphatic metastasis, and by which mechanisms.

Hypercholesterolemia is a type of dyslipidemia, characterized by increased low-density lipoprotein (LDL) cholesterol in the plasma. LDL is susceptible to oxidation by reactive oxygen species (ROS), therefore increasing lipid peroxidation in the tissue or plasma (13). Additionally, there is increasing evidence indicating that oxidized LDL (oxLDL) is a common pathogenic factor in cardiovascular diseases, and breast and ovarian cancer $(14,15)$. For example, a previous study indicated that increasing oxLDL is positively associated with cancer development, through binding to the lectin-like oxLDL receptor (LOX) and stimulating inflammation, proliferation and migration pathways (16). However, it has not been reported whether oxLDL could have an initial adverse effect on gastric cancer lymphatic metastasis, and the regulatory mechanisms remain unidentified.

Thus, the purpose of the present study was to investigate the association between the plasma oxLDL levels and the lymph node metastasis in gastric cancer, and then to elucidate the underlying mechanisms.

\section{Materials and methods}

Cell lines and cell culture. Gastric cancer cell lines HGC-27, MGC-803 and AGS were purchased from the American Type Culture Collection (Manassas, VA, USA), and SGC-7901 cells were purchased from the Chinese Academy of Sciences Cell Bank (Shanghai, China). All cell lines were maintained in Dulbecco's modified Eagle's medium (DMEM; Corning Life Sciences, New York, NY, USA) supplemented with $10 \%$ (v/v) fetal bovine serum, $100 \mathrm{U} / \mathrm{ml}$ penicillin and $100 \mathrm{mg} / \mathrm{ml}$ streptomycin, and cultivated in a humidified $37^{\circ} \mathrm{C}$ incubator containing $5 \% \mathrm{CO}_{2}$.
Tissue specimens, clinical and pathological data collection. A total of 17 cases of gastric cancer specimens (mean age, 64.5 years; age range, $50-75$ years; 9 male and 8 female patients), including cancerous and paracancerous tissues used as control, as well as plasma, were collected from the Department of Gastrointestinal Surgery, Traditional Chinese Medicine Hospital of Guangdong Province (Guangzhou, China) from November 2015 to June 2016. Another 11 cases of plasma from patients with gastric cancer (mean age, 67.7 years; age range, 53-76 years; 5 male and 6 emale patients) were collected from the Guangzhou First People's Hospital (Guangzhou, China) from April to June 2016. All cases were histopathologically confirmed as gastric cancer by three pathologists blinded to the present study. All patients provided written informed consent prior to surgery, and the use of medical records and biospecimens was approved by the Institutional Research Ethics Committee of Traditional Chinese Medicine Hospital of Guangdong Province and Guangzhou First People's Hospital.

Native $L D L(n L D L)$ and ox $L D L$ preparation. The density of the human plasma sample was adjusted to $1.200 \mathrm{mg} / \mathrm{ml}$ with $\mathrm{NaBr}$ previously. Subsequently, nLDL, with density between $1.020-1.063 \mathrm{mg} / \mathrm{ml}$, was extracted from human plasma samples by density gradient centrifugation $\left(4^{\circ} \mathrm{C}\right.$ at $6,000 \mathrm{x} \mathrm{g}$ for $6 \mathrm{~h}$ ) with $1.020 \mathrm{mg} / \mathrm{ml} \mathrm{NaBr}$ solution layer (upper layer) and $1.063 \mathrm{mg} / \mathrm{ml} \mathrm{NaBr}$ solution layer (lower layer) in the centrifugation tube. Prior to centrifugation, the solutions were added from bottom to the top in the order: $1.063 \mathrm{mg} / \mathrm{ml} \mathrm{NaBr}$ solution, $1.020 \mathrm{mg} / \mathrm{ml} \mathrm{NaBr}$ solution and $1.200 \mathrm{mg} / \mathrm{ml}$ adjusted human plasma. Following the density gradient centrifugation, the extracted nLDL was located between the $1.063 \mathrm{mg} / \mathrm{ml}$ $\mathrm{NaBr}$ solution and $1.020 \mathrm{mg} / \mathrm{ml} \mathrm{NaBr}$ solution, and then it was collected with an injector. oxLDL was obtained by oxidizing nLDL with $5 \mu \mathrm{M} \mathrm{CuSO}{ }_{4}$ solution at $37^{\circ} \mathrm{C}$ for $18 \mathrm{~h}$. Subsequently, nLDL and oxLDL were purified with a dialysis bag in PBS solution with $200 \mu \mathrm{M}$ EDTA $\left(4^{\circ} \mathrm{C}\right.$ for $\left.24 \mathrm{~h}\right)$. The concentrations were measured with a Lowry's assay (17). Finally, the oxidative activity of oxLDL was determined by Oil Red O (Sigma-Aldrich; Merck KGaA, Darmstadt, Germany) staining (room temperature for $8 \mathrm{~min}$ ) of foaming macrophages RAW264.7 (American Type Culture Collection) treated with oxLDL $\left(37^{\circ} \mathrm{C}\right.$ for $\left.24 \mathrm{~h}\right)$, which was measured by light microscope at $\times 200$ magnification. As the endocytosis of oxidized LDL occurred in macrophages, the macrophages became foaming cells and were stained by Oil Red O.

Animal experiments. Animal experiments using female BALB/c nude mice ( $\mathrm{n}=18,5-6$ weeks old, 18-22 g body weight) were purchased from Beijing Vital River Laboratory Animal Technology Co., Ltd., (Beijing, China). The mice were provided access to food and water ad libitum, and housed under specific pathogen-free conditions with a 12/12 h light/dark cycle, and controlled humidity (40-70\%) and temperature $\left(22 \pm 3^{\circ} \mathrm{C}\right)$. Mice would be removed from the group if they exhibited tumor-associated complications, including signs of emaciation, bleeding, skin ulceration or necrosis; additionally, sick mice were removed from the experiment and sacrificed by cervical dislocation. The mice sacrificed were all mature, and no mice were sacrificed prior to grouping. The restrictions placed on the tumor sizes in the mice specified that they must 
be $<10 \%$ of the weight of the mice $\left(<2,500 \mathrm{~mm}^{3}\right)$. Nude mice were treated with oxLDL for 28 days, and then the volume and weight of tumors were determined. Following the experiment, all the mice were sacrificed by cervical dislocation. The mice were anaesthetized by intraperitoneal injection with $10 \%$ chloral hydrate $(3 \mathrm{ml} / \mathrm{kg}$ body weight) prior to cervical dislocation. All procedures associated with animal handling, experimentation and welfare were conducted in compliance with the Institutional Animal Care and Use Committee of Sun Yat-sen University (approval no. 20151011007; Guangzhou, China).

Popliteal lymph node metastasis model. HGC-27 cells $\left(2 \times 10^{6}\right)$ previously infected with pLenti-CMV-EGFP-linker-Luc-P GK-Puro virus (Obio Biotech Corp., Ltd., Shanghai, China) were inoculated subcutaneously into the footpads of the nude mice. Following the tumor volume reaching $\sim 100 \mathrm{~mm}^{3}$, fluorescein luciferin (Promega Corporation, Madison, WI, USA) was injected intraperitoneally, and then the footpad tumors were imaged with a spectroscopic IVIS (PerkinElmer, Inc., Waltham, MA, USA). Subsequently, the mice were randomized into three groups, the control, nLDL and oxLDL groups. The latter two treatment groups were injected in the tail vein with $5 \mu \mathrm{g} / \mathrm{g}$ body weight $\mathrm{nLDL}(5 \mathrm{mg} / \mathrm{ml})$ or oxLDL $(5 \mathrm{mg} / \mathrm{ml})$, respectively, every two days while the control group was treated with the same volume of PBS. At 21 days after the first administration, in vivo imaging of the footpad transplanted tumors and the popliteal lymph nodes metastatic tumors was conducted with a spectroscopic IVIS. The mice were then sacrificed at day 28 , and the tumors were excised, dissected and weighed. Tumor volume was calculated with the following formula: Volume $\left(\mathrm{mm}^{3}\right)=\left(\right.$ length $\mathrm{x}$ width $\left.{ }^{2}\right) / 2$.

VEGF-C expression levels in HGC-27, AGS, MGC-803 and SGC-7901 cell lines are sensitive to oxLDL. Thus, all of these cell lines are suitable for in vitro signaling experiments. According to the outcomes of our preliminary animal experiments, the tumor formation rate of HGC-27 cells was highest amongst all of the cell lines tested. Considering this, HGC-27 was selected to start the animal experiments, and for later in vivo and in vitro experiments.

Tube formation assay. A human lymphatic endothelial cells (hLECs) in vitro tube formation assay was performed by first pipetting $200 \mu \mathrm{l}$ Matrigel (BD Biosciences, Franklin Lakes, NJ, USA) into each well of a 24-well plate, which was then polymerized for $30 \mathrm{~min}$ at $37^{\circ} \mathrm{C}$. hLECs $\left(2 \times 10^{4}\right.$ cells; Procell Life Technology Co., Ltd., Wuhan, China) in $200 \mu \mathrm{l}$ conditioned medium (the culture medium from HGC-27 cells treated with oxLDL) were added to each well and incubated at $37^{\circ} \mathrm{C}$ in an atmosphere containing $5 \% \mathrm{CO}_{2}$ for $12 \mathrm{~h}$. Images were captured using a bright-field with ZEISS Axio Observer Z1 (Carl Zeiss AG, Oberkochen, Germany).

ELISA. A collection of clinical samples, including fresh plasma, cancerous and paracancerous tissues all obtained from the same patient with gastric cancer were preserved in liquid nitrogen $\left(-196^{\circ} \mathrm{C}\right)$; ELISAs were performed according to the manufacturer's protocols of the ELISA test kits. Firstly, for the tissue ELISA experiment, the tissues were broken up by a homogenizer and with ultrasonication, and the concentration of total protein in each sample was determined with the bicinchoninic acid (BCA) method. Subsequently, the concentration of VEGF-C was normalized to the concentration of total protein. Secondly, for the collection of cell culture supernatants, the gastric cancer cell lines (SGC-7901 and HGC-27) seeded $\left(5 \times 10^{4}\right.$ cells $\left./ 500 \mu \mathrm{l}\right)$ in 6 -well culture plates were cultured in growth medium until they reached $70-80 \%$ confluency, and were then treated with $50 \mu \mathrm{g} / \mathrm{ml} \mathrm{nLDL}$ or oxLDL for $24 \mathrm{~h}$ as aforementioned, while PBS was used in place of this for the control group, and then the supernatants were collected. Finally, the supernatants were centrifuged $\left(4^{\circ} \mathrm{C}\right.$ at $300 \mathrm{x} \mathrm{g}$ for $\left.10 \mathrm{~min}\right)$, and the concentration of oxLDL and VEGF-C was measured using an ELISA kit specific for VEGF-C (oxLDL kit; cat. no. STA-388; Cell Biolabs, Inc., San Diego, CA, USA; and VEGF-C kit; cat. no. DVEC00; R\&D Systems, Inc., Minneapolis, MN, USA). The procedure steps were conducted according to the manufacturer's protocols.

Nucleoprotein extraction. HGC-27 cells were treated with $50 \mu \mathrm{g} / \mathrm{ml} \mathrm{nLDL}$, oxLDL or PBS for $12 \mathrm{~h}$ at $37^{\circ} \mathrm{C}$, prior to extraction of total protein, following which a Nucleoprotein Extraction kit (Thermo Fisher Scientific, Inc., Waltham, MA, USA) was used according to the manufacturer's protocols. The procedural steps were conducted according to the manufacturer's protocols. Subsequently, the content of P65, histones (internal reference for nucleoprotein) and $\beta$-actin (internal reference for cytoplasmic protein) among the total nucleoprotein was detected by western blot analysis, according to the subsequent protocol.

Western blotting. The antibodies used for western blotting were: Rabbit polyclonal to human LOX-1 antibody (dilution, 1:500; cat. no. sc-20753; Santa Cruz Biotechnology, Inc., Dallas, TX, USA); rabbit monoclonal to human phospho-IкB kinase $\alpha$ $(\mathrm{p}-\mathrm{IKK} \alpha)($ Ser176)/IKK $\beta$ (Ser177) antibody (dilution, 1:1,000; cat. no. CST\#2078); rabbit polyclonal to human IKK $\alpha$ antibody (dilution, 1:1,000; cat. no. CST\#2862); rabbit monoclonal to human p-inhibitor of $\kappa \mathrm{B} \alpha(\mathrm{I} \kappa \mathrm{B} \alpha$ ) (Ser32) antibody (dilution, 1:1,000; cat. no. CST\#2859); rabbit monoclonal to human I $\mathrm{B} \alpha$ antibody (dilution, 1:1,000; cat. no. CST\#4812); rabbit monoclonal to human p-P65 (Ser536) antibody (dilution, 1:1,000; cat. no. CST\#3033); rabbit monoclonal to human P65 antibody (dilution, 1:1,000; cat. no. CST\#8242); rabbit polyclonal to human VEGF-C antibody (dilution, 1:1,000; cat. no. CST\#2445); rabbit polyclonal to human $\beta$-actin antibody (dilution, 1:5,000; cat. no. CST\#3700); rabbit monoclonal to human Histone H3 (D1H2) antibody (dilution, 1:5,000; cat. no. CST\#3700); and mouse monoclonal to human $\beta$-tubulin (D3U1W) antibody (dilution, 1:2,000; cat. no. CST\# 86298) (all from Cell Signaling Technology, Inc., Danvers, MA, USA). All antibodies were incubated for $12 \mathrm{~h}$ at $4^{\circ} \mathrm{C}$. The secondary antibody goat anti-rabbit [1:2,000, horseradish peroxidase (HRP) conjugate; cat. no. 31460] and goat anti-mouse $(1: 2,000$, HRP conjugate; cat. no. 31430) (both from Thermo Fisher Scientific, Inc.) were incubated for $4 \mathrm{~h}$ at $4^{\circ} \mathrm{C}$. Additionally, $10 \%$ non-fat milk (cat. no. 100-04504-SDS; Bio-Rad Laboratories, Inc., Hercules, CA, USA) was applied as a blocking reagent ( $1 \mathrm{~h}$ at room temperature). A total of $20 \mu \mathrm{M}$ pyrrolidine dithiocarbamic acid, ammonium salt (PDTC; cat. no. \#P8765; Sigma-Aldrich; Merck KGaA) was used as an 
inhibitor of nuclear factor (NF)- $\mathrm{B}$ activation and $250 \mu \mathrm{g} / \mathrm{ml}$ polyinosinic acid (Poly I; cat. no. P4154; Sigma-Aldrich; Merck $\mathrm{KGaA})$ as a LOX-1 inhibitor.

The cells (AGS, SGC-7901, MGC-803 and HGC-27) were lysed with $1 \mathrm{X}$ SDS and the total protein was extracted. The protein concentration was determined using a BCA protein quantitation kit (Nanjing KGI Biological Technology Development Co., Ltd., Nanjing, China), according to the manufacturer's protocol. Aliquots of equal amounts of protein $(30 \mu \mathrm{g})$ [containing loading buffer: sodium lauryl sulfate, glycerol, bromophenol blue and tris (hydroxymethyl) aminomethane] from the lysates were loaded onto a $10 \%$ SDS-PAGE gel, and then electrophoresis was conducted at $80 \mathrm{~V}$ (constant voltage) until the markers had separated fully. A piece of polyvinylidene fluoride membrane was cut according to the size of the gel, and it was incubated in methanol for $\sim 10 \mathrm{sec}$ on a rocker at room temperature prior to use. Subsequently, a gel-membrane sandwich was arranged and the electrodes were attached, and then the power supply was set to $300 \mathrm{~mA}$ (constant current) for $3 \mathrm{~h}$ at $4^{\circ} \mathrm{C}$. Following this, $10 \%$ milk in TBS with $0.1 \%$ Tween-20 (TBST) buffer was prepared, the membranes were rocked in TBST gently for $1 \mathrm{~h}$ at room temperature, and then the membranes were washed with TBST buffer three times, for $10 \mathrm{~min}$ each time. Additionally, the primary antibodies (anti-LOX-1, anti-IKK, anti-p-IKK, anti-IкB, anti-p-IкB, anti-P65, anti-p-P65, anti-VEGF-C and anti- $\beta$-actin) was added at the corresponding dilution in TBST buffer (containing 5\% bovine serum albumin; cat. no. SW3015; Beijing Solarbio Science \& Technology Co., Ltd., Beijing, China). The membrane was incubated at $4^{\circ} \mathrm{C}$ for $\sim 12 \mathrm{~h}$, and then the first antibody solution was poured out and the membrane was washed three times with TBST buffer for $10 \mathrm{~min}$ each. Subsequently, the secondary antibodies (goat anti-mouse $\mathrm{IgG}$ and goat ant-rabbit $\operatorname{Ig} G$ ) was added at the corresponding dilution in TBST buffer (containing 2\% bovine serum albumin). This was incubated at $4^{\circ} \mathrm{C}$ for $\sim 4 \mathrm{~h}$, following which the secondary antibody solution was poured out and the membrane was washed three times with TBST buffer for $10 \mathrm{~min}$ each. Following this, the TBST buffer from the membranes was poured out, and an enhanced chemiluminescent solution (Applygen Technologies, Inc., Beijing, China) was added, with exposure to X-ray film and imaging with an ImageQuant LAS 4000 mini being performed. Gray level scanning was performed using ImageJ software (Version 1.48; National Institutes of Health, Bethesda, MD, USA), and the results were normalized to $\beta$-actin in order to analyze the changes in target protein expression.

RNA interference. LOX-1 siRNA and a non-specific control siRNA (NCsiRNA) were purchased from Guangzhou RiboBio Co., Ltd. (Guangzhou, China). siLOX-1-1, sense, 5'-AGGACG GUUCUCCUUUGAUdTdT-3', and anti-sense, 3'-dTdTUCCU GCCAAGAGGAAACUA-5'; siLOX-1-2, sense, 5'-CAGGUA CCUGUGCAUAUAUdTdT3', and antisense, 3'-dTdTGUCCA UGGACACGUAUAUA-5'; and siLOX-1-3, sense, 5'-CGAACU CAAGGAAAUGAUAdTdT-3', and antisense, 3'-dTdTGCUU GAGUUCCUUUACUAU-5'.

Transfection was performed according to the manufacturer's protocols of the interference kit (Guangzhou RiboBio Co.,
Ltd.). When HGC-27 gastric cancer cells were grown to $\sim 60 \%$ confluency, riboFECT (Guangzhou RiboBio Co., Ltd.) was used for transfection. For each transfection reaction, transfection complexes were prepared at room temperature using $20 \mathrm{nM}$ siLOX-1 or NCsiRNA, incubated at $37^{\circ} \mathrm{C}$ for $10 \mathrm{~min}$ and then added to the serum-free DMEM. RNA and proteins were collected $24 \mathrm{~h}$ after transfection and the effect of interference was determined by reverse transcription-quantitative polymerase chain reaction (RT-qPCR) or western blot analysis, as aforementioned. Cells were used for other experiments 24-72 $\mathrm{h}$ after transfection.

$R T-q P C R$. Total RNA was extracted from HGC-27 and SGC-7901 gastric cancer cell lines using a total RNA extraction kit (Qiagen China Co., Ltd., Shanghai, China) according to the manufacturer's protocols. Subsequently, 500 ng RNA was reverse transcribed using a PrimeScript Reverse Transcription kit (Takara Bio, Inc., Otsu, Japan), and then qPCR was configured using SYBR ${ }^{\circledR}$ II Premix Ex Taq ${ }^{\mathrm{TM}}$ (Takara Bio, Inc.). Finally, a LightCycler ${ }^{\circledR} 2.0$ system (Roche Diagnostics, Basel, Switzerland) was used for RT-qPCR analysis. Primer sequences were as follows: human LOX-1, sense, 5'-CCCTTGCTCGGAAGCTGAAT-3', and antisense, 5'-GCT TGCTGGATGAAGTCCTGAA-3'; human VEGF-C, sense 5'-AGAGCCGAGGGCAAAAGT-3', and antisense 5'-GCTGA GGTCCTCTCCTGGTC-3'; and human $\beta$-actin, sense, 5 '-ACT CTTCCAGCCTTCCTTC-3', and antisense, 5'-ATCTCCTTCT GCATCCTGTC-3'. These primers were all synthesized by GeneRay Biotech Co., Ltd. (Shanghai, China). $\beta$-actin was used as an internal control and all samples were assayed in triplicate.

Cycling conditions were as follows: Preheat for $95^{\circ} \mathrm{C}$ for $30 \mathrm{sec}$ for $1 \mathrm{cycle}$, and amplification at $95^{\circ} \mathrm{C}$ for $10 \mathrm{sec}$ and $60^{\circ} \mathrm{C}$ for $45 \mathrm{sec}$ for 40 cycles. Data were analyzed using the $2-^{\Delta \Delta \mathrm{Cq}}$ method (18), and $\beta$-actin was used as the internal reference gene.

Immunofluorescence. Gastric cancer cells (HGC-27) were seeded $\left(1 \times 10^{4}\right.$ cells $/ \mathrm{ml}$ DMEM medium) in petri dishes and treated with $50 \mu \mathrm{g} / \mathrm{ml} \mathrm{nLDL}$ or oxLDL for $12 \mathrm{~h}$ at $37^{\circ} \mathrm{C}$. Cells were washed three times with PBS and fixed in $4 \%$ paraformaldehyde for $15 \mathrm{~min}$ at room temperature. The non-specific binding sites of the cells were then blocked with normal non-immunized goat serum (Dako; Agilent Technologies, Inc., Santa Clara, CA, USA) for $1 \mathrm{~h}$ at $37^{\circ} \mathrm{C}$, and then the cells were washed three times with PBS. A rabbit polyclonal to human NF- $\mathrm{NB}$ p65 antibody (dilution, 1:200; cat. no. ab16502; Abcam, Cambridge, MA, USA) was added and the membranes were incubated overnight at $4{ }^{\circ} \mathrm{C}$, following which the secondary antibody (anti-rabbit; Alexa Fluor 488 conjugate; dilution, 1:1,000; cat. no. A-11029; Thermo Fisher Scientific, Inc.) was added for $1 \mathrm{~h}$ at room temperature. Finally, cell nuclei were stained with DAPI (Sigma-Aldrich; Merck $\mathrm{KGaA}$ ) for $10 \mathrm{~min}$ at room temperature. The coverslips were then added, and the cells were imaged at x200 magnification using a laser confocal microscope (Carl Zeiss).

Immunohistochemistry. Tissues were surgically resected, fixed in formalin (37\%; overnight at room temperature) and embedded in paraffin. Subsequently, $5-\mu \mathrm{m}$ thick histological 
sections were prepared. The sections were treated with the blocking solution $\left(3 \% \mathrm{H}_{2} \mathrm{O}_{2}\right)$ and normal goat serum (Boster Biological Technology, Pleasanton, CA, USA) to block non-specific background binding for $1 \mathrm{~h}$ at $37^{\circ} \mathrm{C}$. Sections were then incubated with a mouse monoclonal antibody specific to D2-40 (1:200, dilution; cat. no. ab77854; Abcam). Following an overnight incubation at $4^{\circ} \mathrm{C}$, sections were incubated with the secondary antibody from the EnVision ${ }^{\mathrm{TM}}$ Detection Kit (peroxidase/DAB-conjugated, anti-rabbit/mouse; cat. no. K500705; Dako; Agilent Technologies, Inc.) at room temperature for $20 \mathrm{~min}$, and then incubated with enzyme conjugate (horseradish peroxidase-streptavidin) under the same conditions (all steps were performed according to the manufacturer's protocols). The vessels were revealed with the streptavidin-peroxidase complex followed by the chromogenic substrate 3,3'-diaminobenzidine, and the tissue sections were counterstained with hematoxylin for $20 \mathrm{sec}$ at $37^{\circ} \mathrm{C}$. Lymphatic vessel density (LVD) was determined by calculating the tube number per x100 field of view. Sections were imaged at x100 magnification with a light microscope (Leica Microsystems, GmbH, Wetzlar, Germany).

Statistical analysis. All data are presented as the means \pm standard deviations. The data were analyzed using SPSS 21.0 software (IBM Corp., Armonk, NY, USA). One-way analysis of variance (ANOVA) was used to analyze the differences between groups, followed by Fisher's least significant difference test. Following confirming the data obeyed bivariate normal distribution, Pearson's correlation analysis was used to determine the correlation between LVD and plasma oxLDL, LVD and plasma VEGF-C, and plasma VEGF-C and plasma oxLDL. Pearson's correlation analysis was performed with GraphPad Prism 5 software (GraphPad Software, Inc., La Jolla, CA, USA) to determine the correlation coefficient. $\mathrm{P}<0.05$ was considered to indicate a statistically significant difference.

\section{Results}

Level of oxLDL in the plasma of patients with gastric cancer is positively correlated with the lymphatic metastasis of gastric cancer cells. Clinical studies demonstrated that there is an association between hyperlipidemia and gastric cancer metastasis (2,3). Furthermore, patients with gastric cancer and hyperlipidemia have an increased risk of lymphatic metastasis, compared with patients without hyperlipidemia (19). OxLDL was reported to be associated with the development of various tumor types, including breast, cervical and ovarian cancer $(14,15)$. However, whether oxLDL in patients with hyperlipidemia would promote the lymph node metastasis of gastric cancer remains unknown. To verify this scientific hypothesis, plasma samples from 28 patients with gastric cancer were collected and the concentration of oxLDL was detected via ELISAs. Subsequently, the association between oxLDL levels and lymph node metastasis in gastric cancer was analyzed. As depicted in Fig. 1A, the concentration of oxLDL in plasma was significantly increased at higher stages of lymph node metastasis.

Correlation analysis indicated that there was a positive correlation between the oxLDL concentration and LVD in cancer tissues (Fig. 1B; $\mathrm{r}=0.79 ; \mathrm{P}<0.05$ ). VEGF-C is a predominant factor for lymphangiogenesis (20), and the present data verified its consistent effect in gastric cancer cells (Fig. 1C), highlighting the importance of VEGF-C in the lymphatic metastasis process of gastric cancer. Lymphangiogenesis is an important step in the process of lymphatic metastasis (21). To confirm if gastric cancer lymph node metastasis is associated with lymphangiogenesis stimulated by oxLDL, the LEC-specific marker D2-40 was used to stain lymphatic vessels in gastric cancer samples and matched adjacent tissues. Subsequently, the LVD, which can reflect the degree of lymphangiogenesis (20), was calculated. The results demonstrated that LVD was significantly increased in gastric cancer tissues, compared with adjacent tissues (Fig. 1D). In vitro experiments also demonstrated that oxLDL treatment significantly promoted lymphangiogenesis in the cancer cell microenvironment, compared with the control group (Fig. 1E). These results indicate that oxLDL may be a notable risk factor for lymph node metastasis in gastric cancer, due to stimulating lymphangiogenesis.

OxLDL promotes the lymph node metastasis of gastric cancer in vivo. To investigate the direct effect of oxLDL on the lymph node metastasis of gastric cancer in vivo, a footpad-popliteal lymph node metastasis model was constructed. Following nude mice being treated with oxLDL for 28 days, it was determined that the volume of tumors from the ox-LDL-treated group was decreased, compared with the control group (Fig. 2A and B). Additionally, although the weight of tumors was also decreased in the ox-LDL-treated group, there was no significant statistical differences among the three groups (Fig. 2C). However, the volume and weight of popliteal lymph nodes in oxLDL-treated nude mice were significantly increased, compared with the control nude mice (Fig. 2D-F). Therefore, these results indicate that oxLDL could significantly promote the lymph node metastasis of gastric cancer, an effect that was independent of increasing tumor cell proliferation. Previous studies demonstrated that tumor-induced inflammation could also result in enlarged lymph nodes $(19,22,23)$. To confirm that the enlargement of popliteal lymph nodes in nude mice was due to metastasized gastric cancer cells rather than tumor-induced inflammation, the metastasized gastric cancer cells were traced via live imaging with IVIS system. Prior to footpad injection, the HGC-27 cells were labeled with luciferase and then observed with the IVIS system as described previously (24). Finally, the results demonstrated that there were increased popliteal lymph node metastatic cancer cells migrating from footpad xenografts in the nLDL and oxLDL groups, compared with the control group, whilst oxLDL promoted lymphatic metastasis, primarily from orthotopic implantation (Fig. 2G). These results indicate that oxLDL has a significant role in promoting the lymph node metastasis of gastric cancer.

Concentration of plasma oxLDL in patients with gastric cancer is positively correlated with the plasma VEGF-C. The previous data confirmed the role of oxLDL in promoting the lymph node metastasis of gastric cancer, but the molecular mechanism remains unclear. On the basis of previous studies, including our own $(24,25)$, VEGF-C is a verified major VEGF 

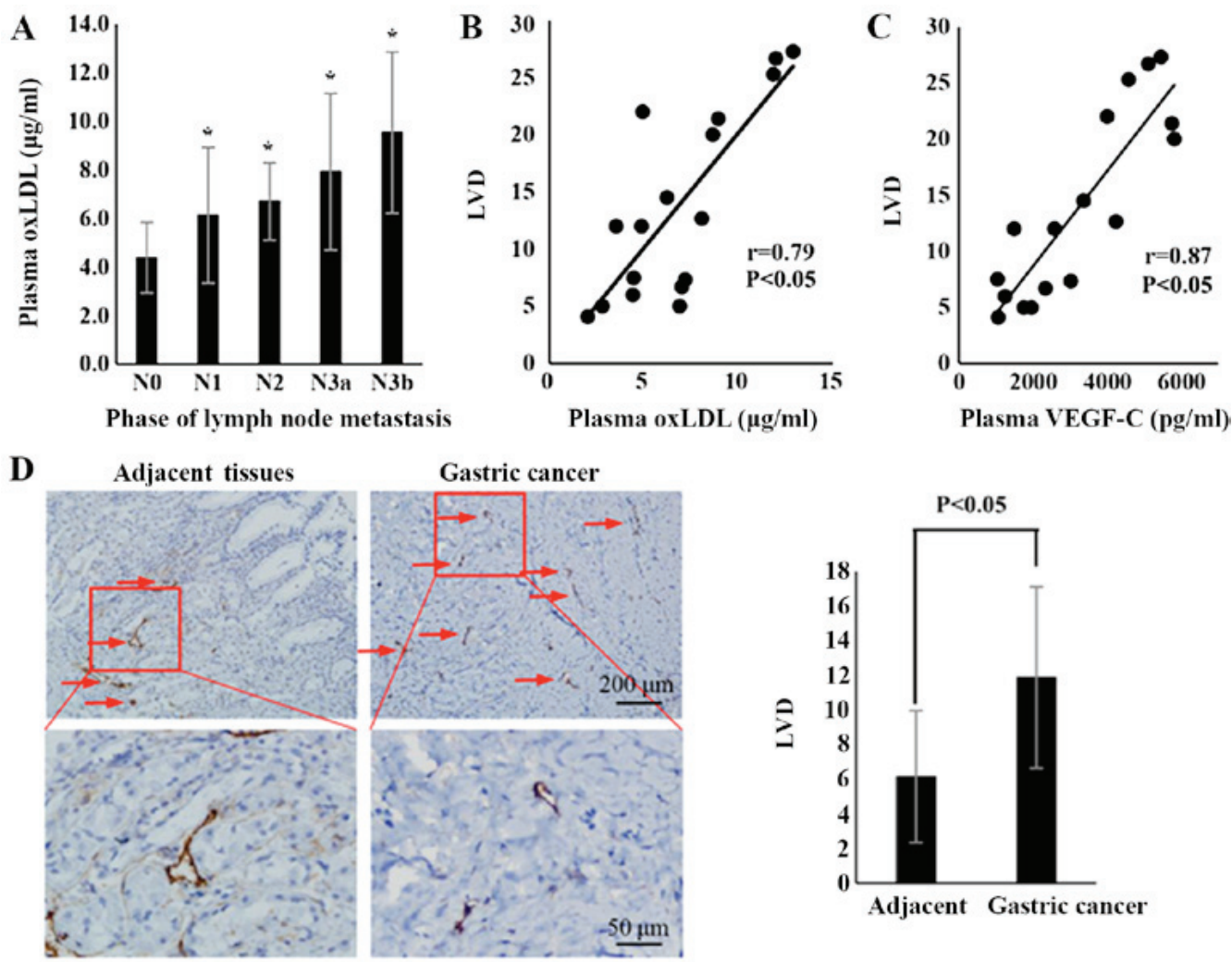

E Ctrl

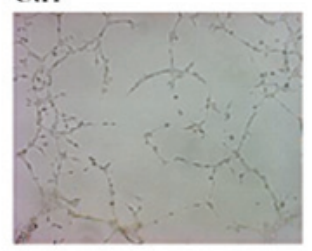

oxLDL

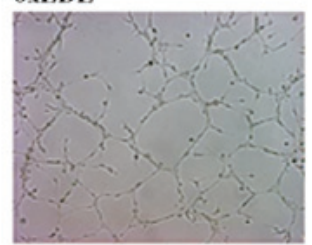

nLDI.

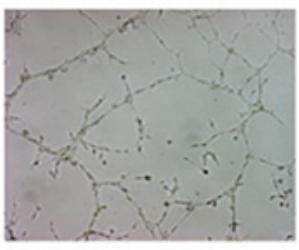

siLOX-1 + oxLDI

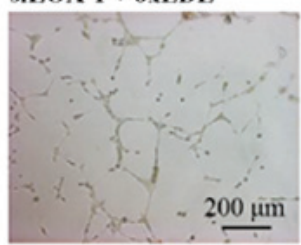

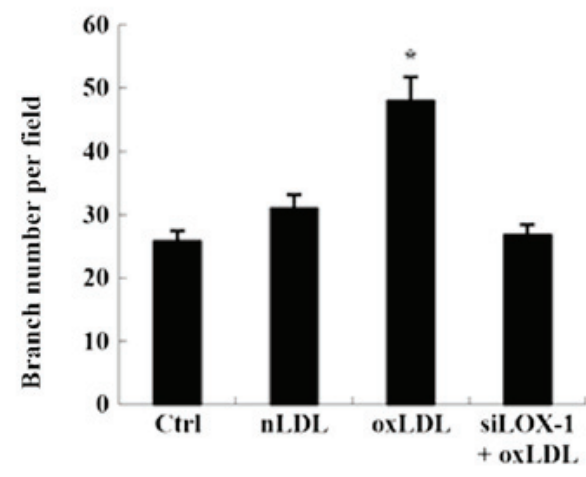

Figure 1. Plasma oxLDL in patients with gastric cancer is positively correlated with lymph node metastasis. (A) The association between plasma oxLDL and lymph node metastasis in gastric cancer (case numbers: $\mathrm{N} 0=8, \mathrm{~N} 1=4, \mathrm{~N} 2=4, \mathrm{~N} 3 \mathrm{a}=5$ and $\mathrm{N} 3 \mathrm{~b}=7$; " $\mathrm{P}<0.05$, compared with $\mathrm{N} 0$ ). (B) The correlation between the plasma oxLDL and the LVD was determined by Pearson's correlation analysis $(n=17 ; \mathrm{r}=0.79$ and $\mathrm{P}<0.05)$. Plasma oxLDL in patients with gastric cancer was detected via ELISAs. Lymphatic vessels in gastric cancer tissues were stained with D2-40. LVD was calculated using the number of vessels per field. (C) The correlation between the plasma VEGF-C and the LVD. Plasma VEGF-C in patients with gastric cancer was detected by ELISAs ( $\mathrm{n}=17, \mathrm{r}=0.87$ and $\mathrm{P}<0.05$ ). (D) Lymphatic vessel in adjacent tissues and gastric cancer tissues were stained with D2-40 by immunohistochemistry. Histograms represent the number of lymphatic tubes per field (for adjacent and gastric cancer tissues $n=17$ ). (E) Tube formation of LEC incubated with the condition medium from the culture medium of HGC-27 treated by nLDL, oxLDL or siLOX-1+oxLDL for $24 \mathrm{~h}$ ("P $<0.05 \mathrm{vs,} \mathrm{Ctrl).} \mathrm{A} \mathrm{total} \mathrm{of} 2 \times 10^{4}$ human lymphatic endothelial cells were seeded with $200 \mu \mathrm{l}$ conditioned medium in each well and incubated for $12 \mathrm{~h}$, and then the tube formation was observed with microscope. Results are presented as the means \pm standard deviations. N0, no regional lymph node metastasis; N1, 1-2 regional lymph node metastases; N2, 3-6 regional lymph node metastases; N3, 7 or more regional lymph node metastases; N3a, 7-15 regional lymph nodes metastases; N3b, >16 regional lymph nodes with metastasis; LVD, lymphatic vessel density; VEGF-C, vascular endothelia growth factor-C; oxLDL, oxidized low-density lipoprotein; Ctrl, control; nLDL, native LDL, siLOX-1, small interfering lectin-like oxLDL.

that promotes lymphangiogenesis and lymph node metastasis. To investigate the mechanism of oxLDL in promoting lymph node metastasis, the effect of oxLDL on VEGF-C expression in and secretion from gastric cancer cells was examined, and the association between the concentration of plasma oxLDL and VEGF-C in patients with gastric cancer was analyzed. Finally, it was determined that they were positively correlated (Fig. 3A; $r=0.64 ; \mathrm{P}<0.05$ ).
OxLDL promotes the expression and secretion of VEGF-C in gastric cancer cells. To verify the role of oxLDL in promoting VEGF-C expression and secretion in gastric cancer cells, a series of in vitro studies were also conducted. Firstly, the mRNA level of VEGF-C in HGC-27 and SGC-7901 gastric cancer cell lines was detected by RT-qPCR. The results demonstrated that the transcription level of VEGF-C was significantly upregulated following treatment with oxLDL, 


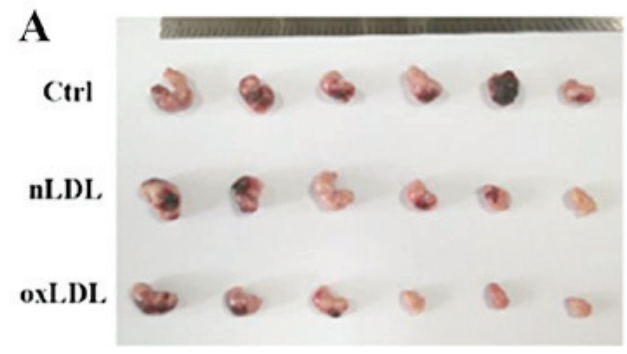

D

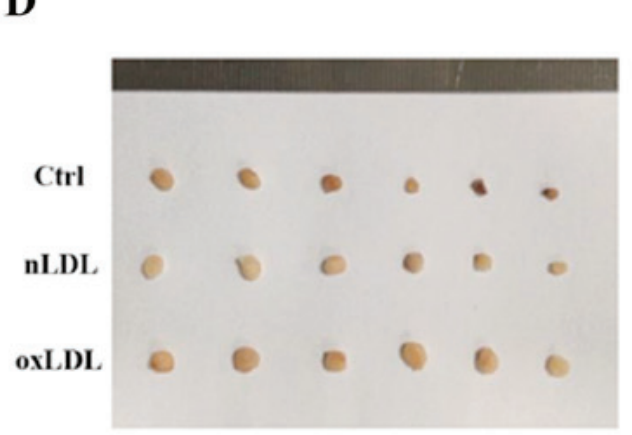

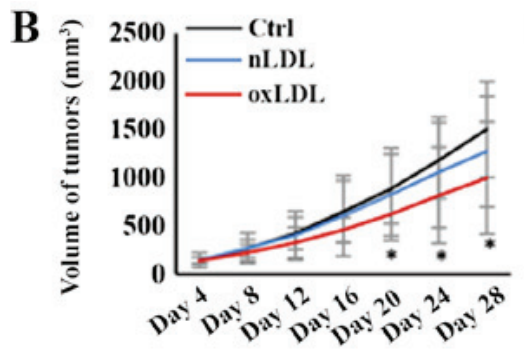

E

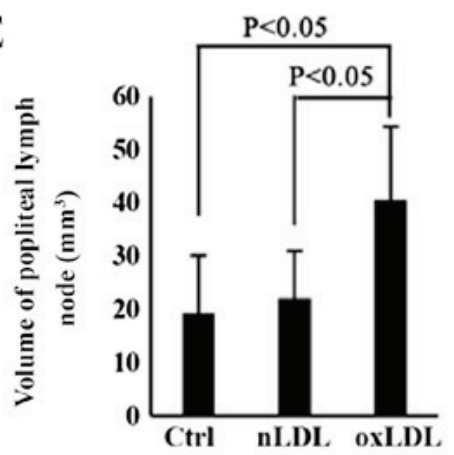

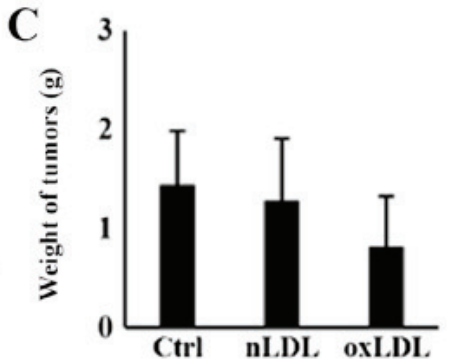

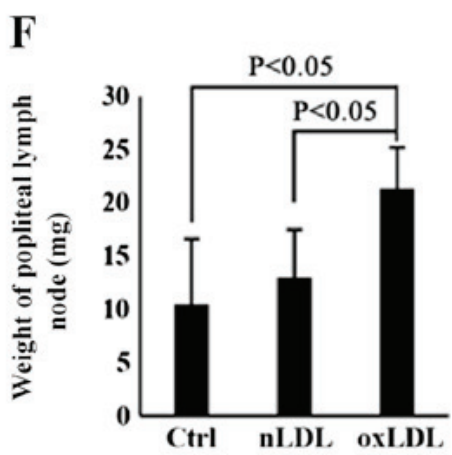

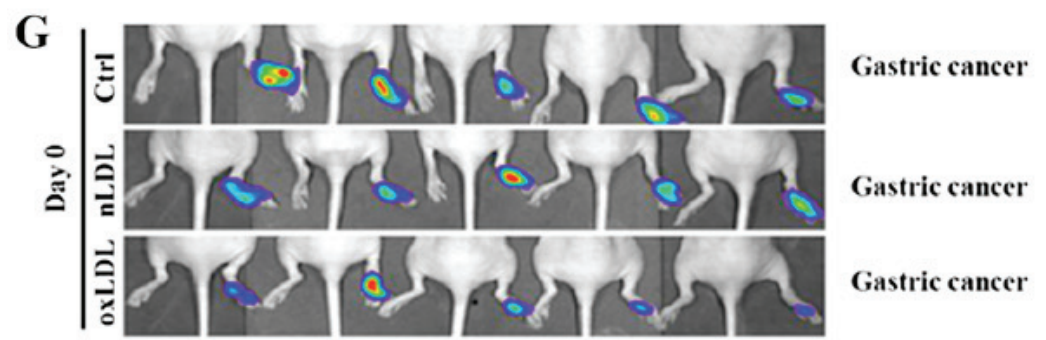

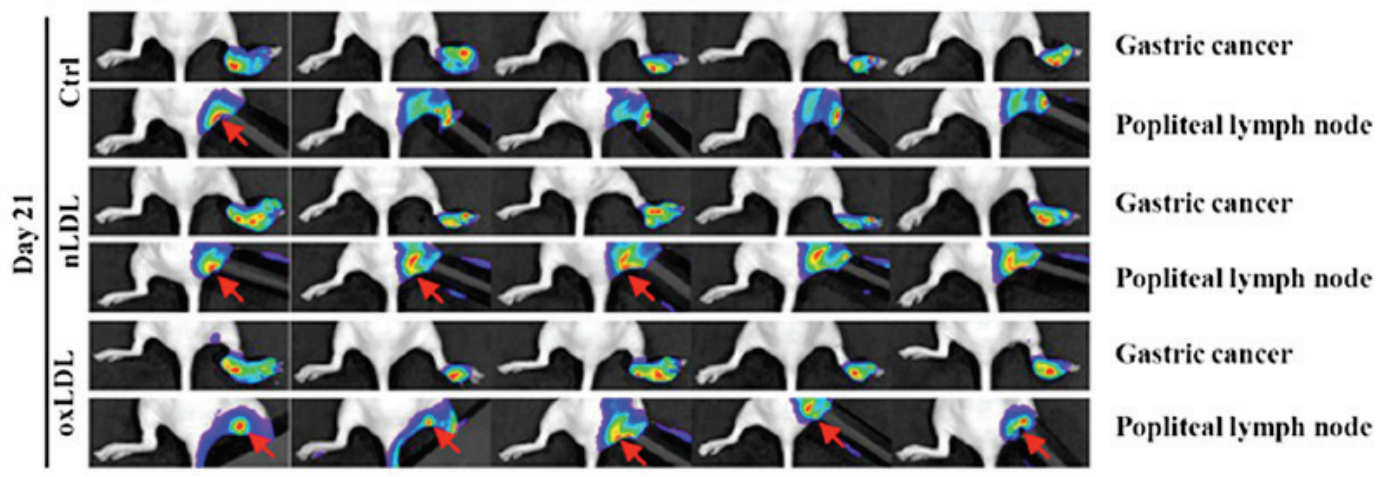

Figure 2. OxLDL promotes the lymph node metastasis of gastric cancer cells in vivo. (A) The general morphology of gastric cancer xenografts from nude mice was depicted following treatment with PBS, nLDL or oxLDL for 28 days. (B) The line chart represents the volume of xenografts (the black line represents the control group, the blue line represents the nLDL group and the red line represents the oxLDL group). (C) The histogram represents the weight of the xenografts. (D) The general morphology of popliteal lymph nodes from animal models following treatment with PBS, nLDL or oxLDL for 28 days. (E) The histogram represents the volume of each group of lymph nodes. (F) The histogram represents the weight of each group of lymph nodes. (G) The gastric cancer cells that had metastasized to the homolateral popliteal lymph nodes were imaged by live IVIS following a luciferin injection. Red arrows represent the metastasized gastric cancer cells that were labeled with luciferase beforehand. Prior to the popliteal lymph nodes being imaged, the footpads of mice were obstructed due to strong signal intensity from the footpad, which was the injection site. The nLDL group, oxLDL group and PBS group contained 6 samples each. The results are presented as the means \pm standard deviations. OxLDL, oxidized low-density lipoprotein; Ctrl, control; nLDL, native LDL.

compared with the nLDL or blank control groups (Fig. 3B). Subsequently, the expression of VEGF-C in oxLDL-treated gastric cancer cells was detected with western blotting and it was determined that oxLDL promoted VEGF-C expression in a dose- and time-dependent manner (Fig. 3C-E). Finally, the level of VEGF-C secretion was measured using an ELISA kit and it was determined that oxLDL also significantly increased the secretion of VEGF-C, compared with the nLDL treatment or blank control groups (Fig. 3F). In summary, oxLDL promotes the expression and secretion of VEGF-C in gastric cancer cells.

OxLDL upregulates VEGF-C expression and secretion in gastric cancer cells by activating the $N F-\kappa B$ signaling pathway. Previous studies, including our own, have revealed that NF- $\kappa \mathrm{B}$ signaling can regulate the expression of VEGF-C $(24,26)$, and that oxLDL can promote the activation of the NF- $\kappa \mathrm{B}$ signaling pathway $(27,28)$. Therefore, the present study investigated 
A

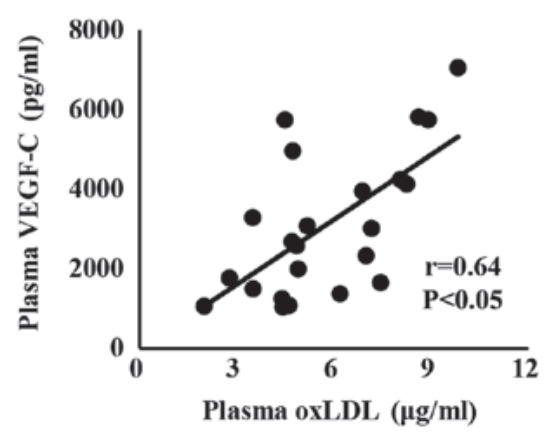

C

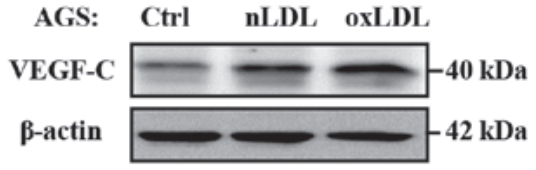

MGC-803: Ctrl nLDL oxLDL

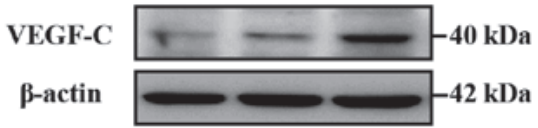

D

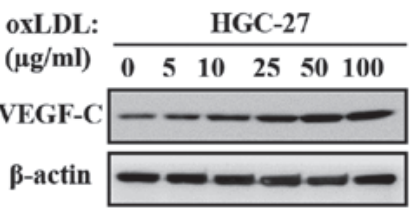

E

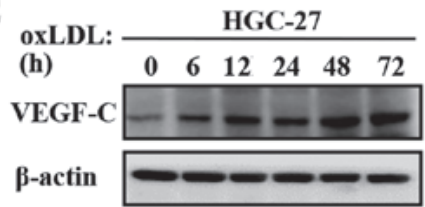

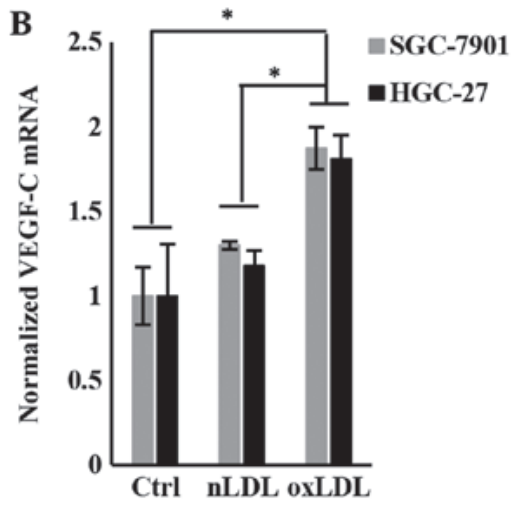

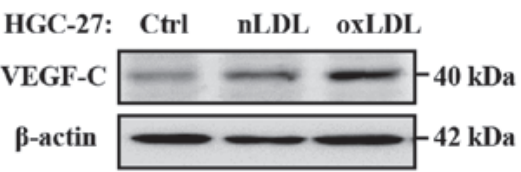

SGC-7901: Ctrl nLDL oxLDL

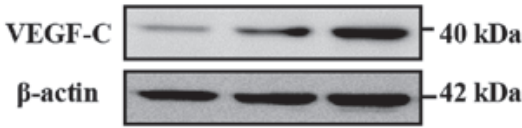

F

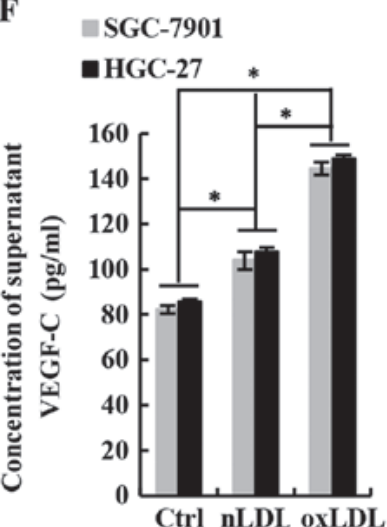

Figure 3. OxLDL promotes the expression and secretion of VEGF-C. (A) Plasma oxLDL was correlated with plasma VEGF-C in patients with gastric cancer. Plasma oxLDL and VEGF-C levels in patients with gastric cancer were detected using ELISA kits. The number of patients was 23 ( $\mathrm{r}=0.64$ and $\mathrm{P}<0.05$ ). (B) VEGF-C mRNA levels in HGC-27 cells treated with $50 \mu \mathrm{g} / \mathrm{ml} \mathrm{nLDL}$ or oxLDL for $24 \mathrm{~h}$, as measured by reverse transcription-quantitative polymerase chain reaction. A total of three independent experiments were performed. (C) VEGF-C expression levels were upregulated by nLDL and oxLDL in AGS, HGC-27, MGC-803 and SGC-7901 gastric cancer cell lines. (D) OxLDL dose-dependently downregulated VEGF-C expression in gastric cancer cells. (E) OxLDL time-dependently downregulated VEGF-C expression in gastric cancer cells. VEGF-C protein levels in cell lysates were measured by western blotting, with $\beta$-actin as the control. (F) To measure the effect of oxLDL on the secretion of VEGF-C by HGC-27 and SGC-7901 gastric cancer cells, VEGF-C was detected in the supernatants using an ELISA kit. ${ }^{*} \mathrm{P}<0.05$, results are presented as the means \pm standard deviations. OxLDL, oxidized low-density lipoprotein; Ctrl, control; nLDL, native LDL; VEGF-C, vascular endothelia growth factor-C.

whether oxLDL regulates the expression and secretion of VEGF-C through the $\mathrm{NF}-\kappa \mathrm{B}$ signaling pathway in gastric cancer cells. To investigate this hypothesis, the following experiments were conducted. Firstly, the HGC-27 gastric cancer cell line was treated with oxLDL, and then activation of the NF- $\mathrm{NB}$ signaling pathway was examined. Western blot analyses (Fig. 4A) revealed that HGC-27 cells incubated with $50 \mu \mathrm{g} / \mathrm{ml}$ oxLDL for various time intervals could sequentially induce increased phosphorylation of $\mathrm{I} \kappa \mathrm{B}$ and $\mathrm{p} 65$. Previous studies confirmed that when the NF- $\kappa \mathrm{B}$ signaling pathway is activated, the transcription factor P65 would be released into the nucleus to regulate the expression of its downstream target genes $(29,30)$. The results of immunofluorescence staining and immunoblotting for nucleoproteins in HGC-27 cells (Fig. 4B and C) demonstrated that oxLDL upregulated the nuclear translocation of P65. Subsequently, the NF-кB signaling inhibitor PDTC was used to antagonize the activating effect of oxLDL, and it was determined that VEGF-C expression and secretion were restored to their original level, to an extent (Fig. 4D and E). As our previous study verified, IKK-dependent phosphorylation of $\mathrm{I} \kappa \mathrm{B}$ and $\mathrm{P} 65$ was responsible for the positive transcriptional regulation of VEGF-C, and demonstrated that P65 was directly involved in the transcription of VEGF-C on the promoter region of VEGF-C using a chromatin immunoprecipitation assay (24). Thus, it is necessary to clarify whether oxLDL mediates the upregulation of VEGF-C by P65. Therefore, P65 was knocked down with siRNA, and it was observed that the upregulation 
A $\mathrm{HGC-27}$

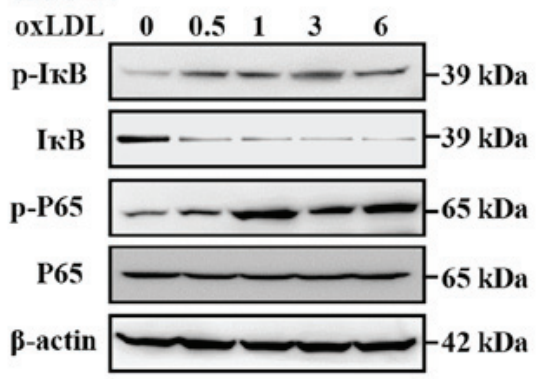

C

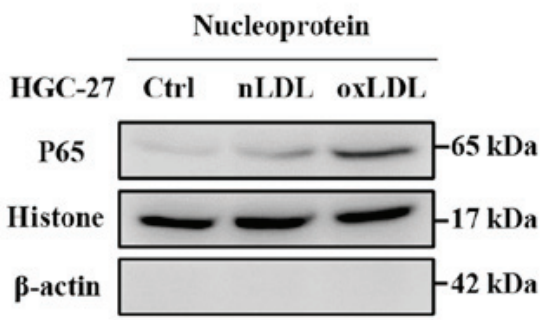

B
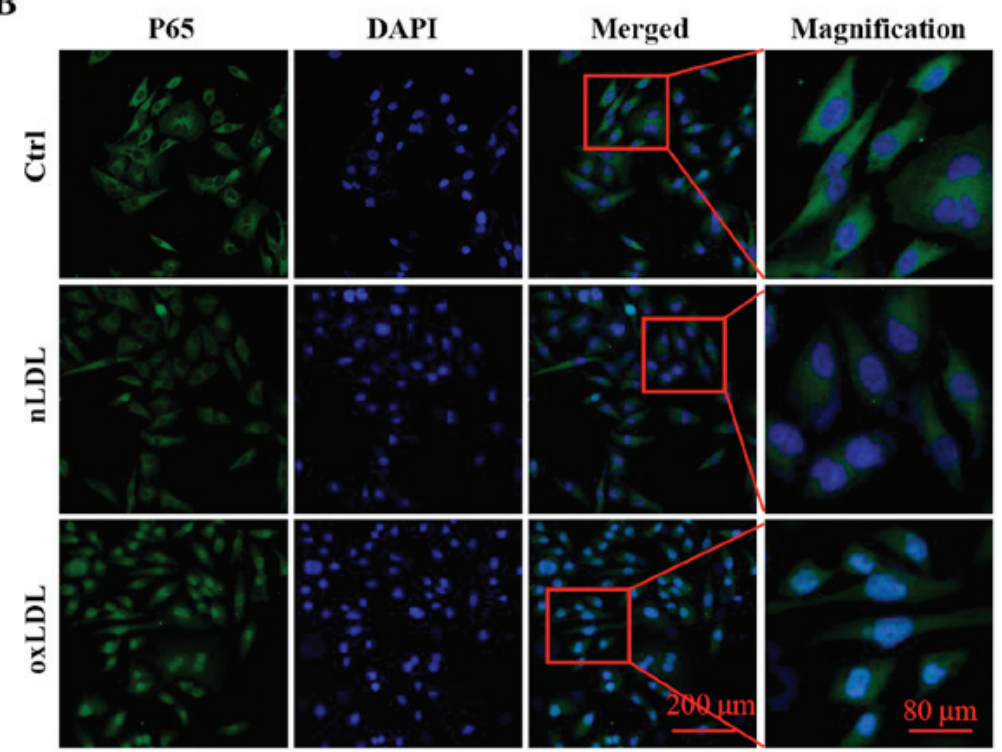

D

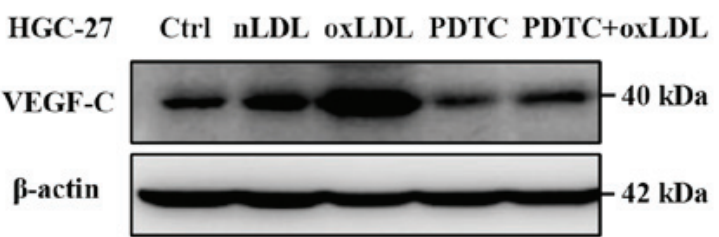

$\mathbf{F}$

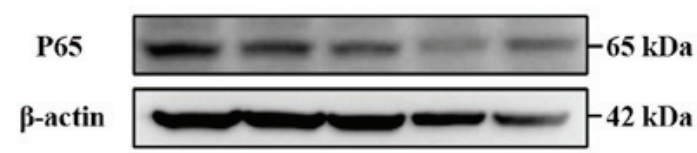

E

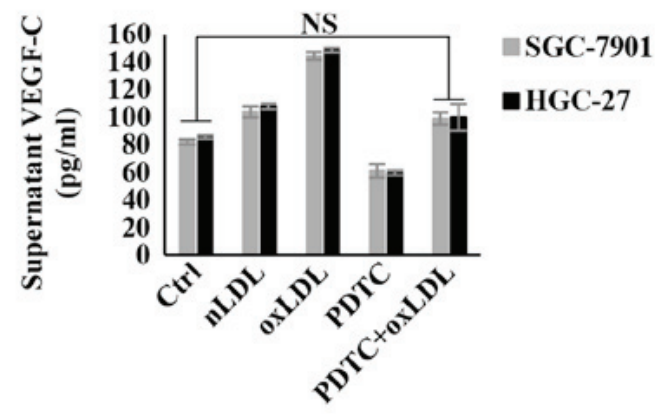

G HGC-27 Ctrl nLDL oxLDL si-p65-2+oxLDL

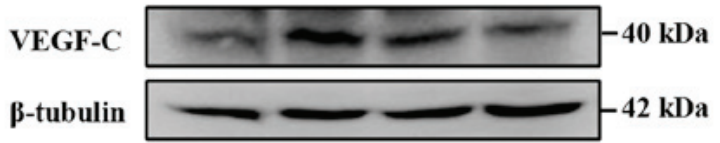

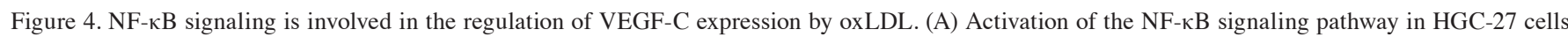
following oxLDL treatment. IкB/p-IкB, P65/p-P65 and $\beta$-actin in gastric cancer cell lysates were measured by western blot analysis. (B) Translocation of NF- $\mathrm{KB}$ and P65 following oxLDL treatment; HGC-27 cells were incubated with $50 \mu \mathrm{g} / \mathrm{ml}$ oxLDL for $6 \mathrm{~h}$. (C) The amount of P65 that was translocated into the nucleus following oxLDL treatment was measured by western blotting. HGC-27 cells were incubated with $50 \mu \mathrm{g} / \mathrm{ml} \mathrm{nLDL}$ and oxLDL for $12 \mathrm{~h}$. (D) The upregulated VEGF-C level was rescued by the NF- $\mathrm{kB}$ inhibitor PDTC. The protein levels were measured via western blotting. (E) VEGF-C levels in the supernatants were detected using an ELISA kit. (F) The knockdown effect of P65 siRNA was verified by western blotting. (G) The upregulated VEGF-C level was rescued by P65 siRNA. P65/p-P65 and VEGF-C protein levels in gastric cancer cell lysates were measured via western blotting. "P $<0.05$, results are presented as the means \pm standard deviations. OxLDL, oxidized low-density lipoprotein; Ctrl, control; nLDL, native LDL; VEGF-C, vascular endothelia

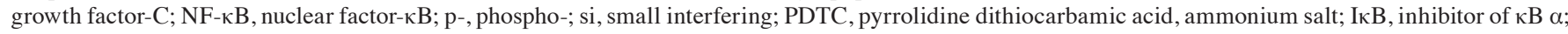
NS, non-significant.

of VEGF-C was inhibited (Fig. 4F and G). These data indicate that oxLDL upregulates VEGF-C expression by promoting NF- $\kappa B$ signaling, which could directly regulate VEGF-C transcription.

OxLDL promotes the activation of the $N F-\kappa B$ signaling pathway and the expression of VEGF-C in gastric cancer cells, mediated by the LOX-1 receptor. Previous studies confirmed that oxLDL could specifically bind to LOX-1, while others reported that LOX-1 mediated the atherogenesis and tumorigenesis of oxLDL $(31,32)$. Thus, it is necessary to examine whether LOX-1 mediates the function of oxLDL to promote VEGF-C expression in gastric cancer cells.
Therefore, LOX-1 was knocked down using siRNA (Fig. 5A) and the expression of VEGF-C was assessed. As depicted in Fig. 5B and $\mathrm{C}$, the expression and secretion of VEGF-C in SGC7901 or HGC-27 cells treated with oxLDL were rescued by siLOX-1. Additionally, the gastric cell lines were pre-treated with $250 \mu \mathrm{g} / \mathrm{ml}$ Poly I, which is a recognized LOX-1 receptor antagonist (33), and it was determined that the expression and secretion of VEGF-C was downregulated, even following oxLDL treatment (Fig. 5D and E). Furthermore, the activation of the NF- $\mathrm{\kappa B}$ signaling pathway was investigated, and it was determined that the phosphorylation of P65, promoted by oxLDL, was rescued via oxLDL/LOX-1 interaction inhibition by Poly I (Fig. 5D). These outcomes indicate that LOX-1 
A

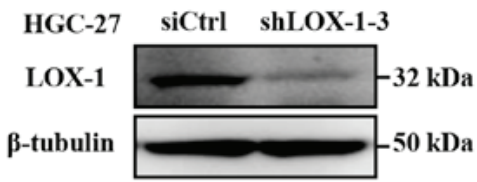

B

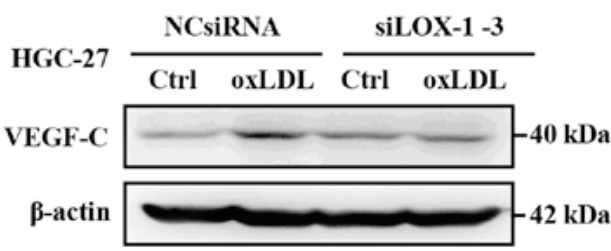

D

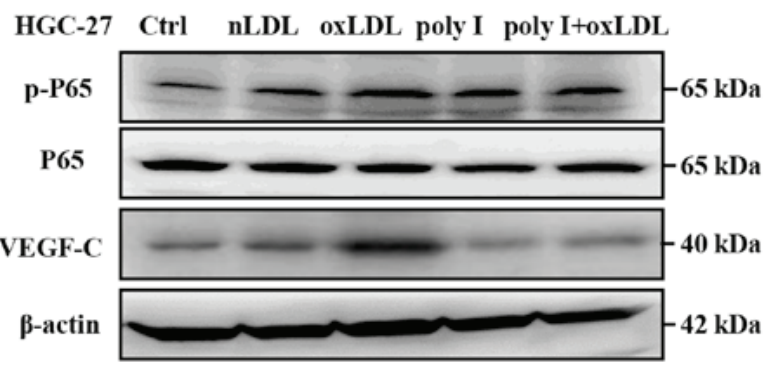

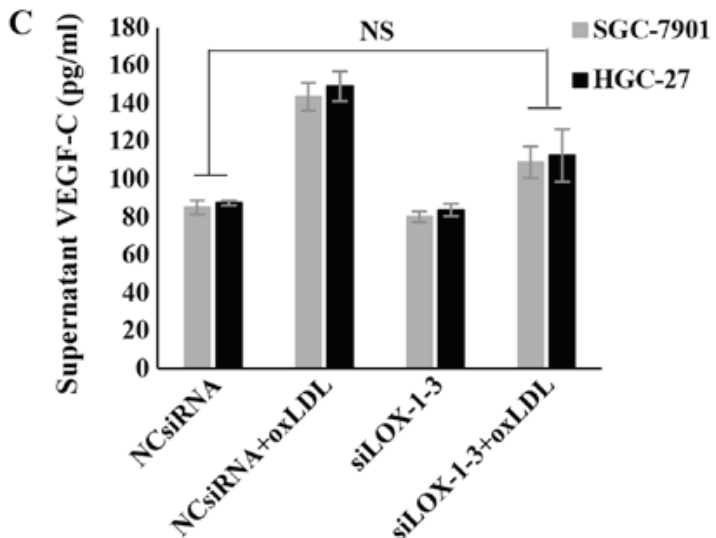

$\mathbf{E}$

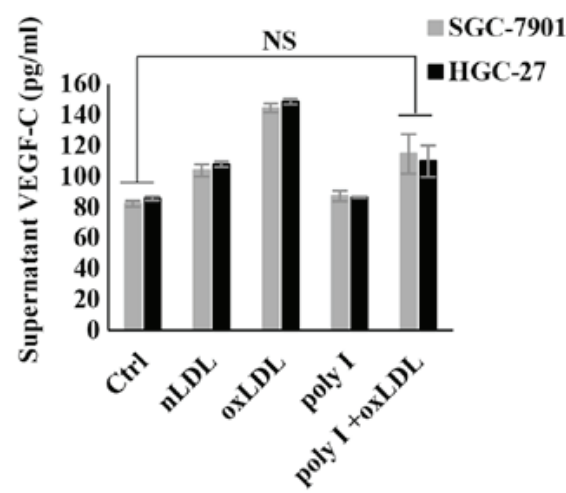

F

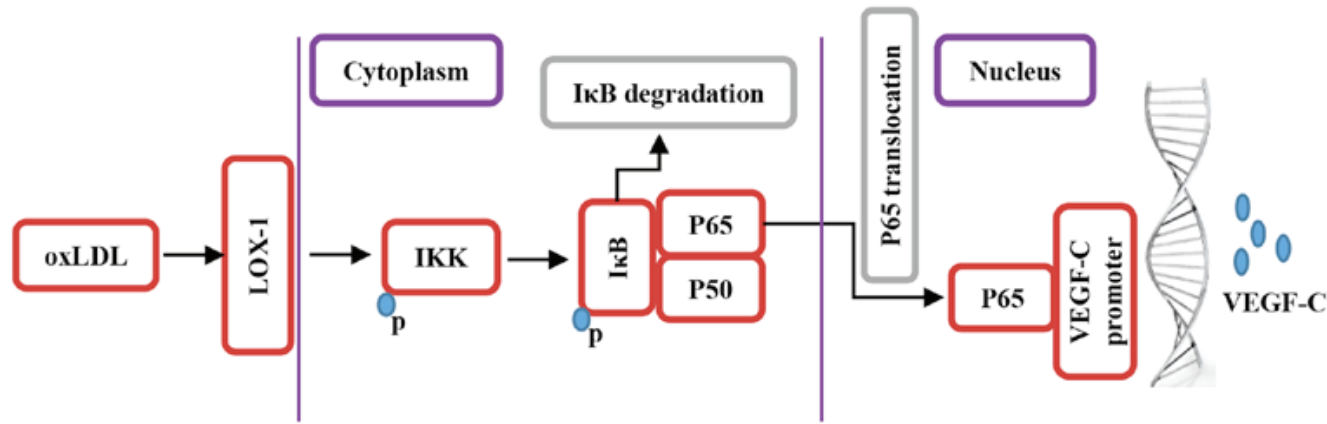

Figure 5. OxLDL promotes the activation of the NF- $\mathrm{kB}$ signaling pathway, as well as the expression and secretion of VEGF-C, through LOX-1. (A) Validation of siRNA efficacy in HGC-27 cells. (B) The effects of oxLDL on NF-kB activity and VEGF-C expression were blocked following the knockdown of LOX-1. VEGF-C protein levels in the cell lysates were measured via western blotting, (C) supernatant VEGF-C levels were detected using an ELISA kit. (D) The regulatory effects of oxLDL on NF-kB activity and VEGF-C expression were blocked following LOX-1 being inhibited by $250 \mu \mathrm{g} / \mathrm{ml}$ Poly I. VEGF-C protein levels in the cell lysates were measured via western blotting, (E) supernatant VEGF-C levels were detected using an ELISA kit. (F) Schematic depicting the mechanism by which oxLDL promotes lymph node metastasis in gastric cancer. Results are presented as the means \pm standard deviations. NS, non-significant;

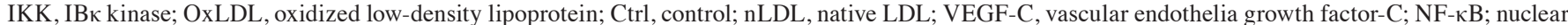
factor-кB; p-, phospho-; si, small interfering; LOX, lectin-like oxLDL; IкB, inhibitor of $\kappa \mathrm{B} \alpha$; NCsiRNA, non-specific control siRNA; poly I, polyinosinic acid.

mediates the activation of the NF- $\kappa \mathrm{B}$ signaling pathway induced by oxLDL, and upregulates the expression and secretion of VEGF-C in gastric cancer cells.

\section{Discussion}

There has been a decline in the incidence of gastric cancer globally, which is currently being attributed to the efficient prevention and treatment of $H$. pylori infection (1); however, it remains the second most common malignancy diagnosed, and a leading cause of cancer-associated mortalities in China in 2012 (1). The reason may lie in the increasing widespread high-fat diet, along with improvements in people's living standards since the 1990s. Over recent years, increasing evidence demonstrated that there is an association between obesity and the malignant progression of gastric cancer $(7,9)$. However, BMI, the standard diagnostic indicator for obesity, cannot definitively predict the incidence and mortality of gastric cancer, while increasing evidence has indicated that hyperlipidemia is more relevant to the progress of gastric cancer than BMI (10-12). The present study indicated that excessive oxLDL, one of the abnormal lipid forma in obesity, has disadvantages with respect to the lymph node metastasis of gastric cancer, which is recognized as an initial and lethal process of cancer spreading.

There is sufficient evidence $(34,35)$, including our previous data (24), to verify that lymphangiogenesis is a primary step for lymphatic metastasis and an important indicator for the 
aggressiveness of malignancies. Furthermore, studies also demonstrated that various malignancies, including breast, ovarian and cervical cancer, could induce the abnormal growth of peripheral lymphatic vessels and increase their permeability by secreting VEGF-C in order to facilitate the lymphatic metastasis of tumor cells $(36,37)$. Thus, LVD was calculated and the expression and secretion of VEGF-C was detected, and it was determined that oxLDL is positively associated with increased lymph node metastasis, in addition to VEGF-C upregulation and lymphangiogenesis stimulation. However, due to the weak correlation $(r=0.64)$ determined between plasma oxLDL and VEGF-C levels and the undetectable oxLDL in tissue sections using immunochemical methods of detection, further in vitro and in vivo experiments were conducted to define whether oxLDL can regulate VEGF-C expression and stimulate lymphangiogenesis. An in vitro study revealed that oxLDL upregulated the expression of VEGF-C in gastric cell lines. Similar results were obtained from the popliteal lymph node metastasis animal experiment. These results demonstrate that the level of oxLDL is associated with VEGF-C expression levels and lymphangiogenesis in gastric cancer, but further clinical studies are required to determine whether oxLDL is an independent marker for the early prediction of gastric cancer lymphatic metastasis. It is also necessary to identify if oxLDL promotes gastric cancer cell spread through lymph vessels or if it enhances the proliferation of cancer cells in lymph nodes. As other studies have demonstrated, elevated oxLDL, or the upregulation of LOX-1 expression, could promote tumor proliferation via ROS generation and cell cycle protein induction $(31,38)$. However, similar phenomenon was not observed in the present gastric cancer implantation models following treatment with oxLDL, and it was tentatively interpreted as the space limitation in the footpad or the loss of gastric cancer cells caused by oxLDL toxicity. Furthermore, to address this point, gastric cancer cells pre-labeled with luciferase were traced using a live imaging system IVIS, and as we had hypothesized, there were increased labeled cells observed in the oxLDL treatment group, compared with the nLDL treatment or blank control groups. In conclusion, oxLDL promoted the lymph node metastasis of gastric cancer independently of increasing cancer cell proliferation.

Lymphangiogenesis is mediated by the balance between stimulating and inhibiting factors, including the regulatory mechanismsinangiogenesis $(39,40)$. Ourpreviousstudyindicated that kallistatin, one of the angiogenesis inhibitors, could impede the $\mathrm{NF}-\kappa \mathrm{B}$ signaling pathway and downregulate the expression of VEGF-C to impair the lymph node metastasis of gastric cancer cells (24). NF- $\kappa \mathrm{B}$ is an important inducible transcription factor that serves an important role in cell growth, proliferation, differentiation, apoptosis and carcinogenesis $(29,30)$. Primarily, $\mathrm{I} \kappa \mathrm{B}$, which covers the nuclear localization sequence of $\mathrm{NF}-\kappa \mathrm{B}$, prevents $\mathrm{P} 65$ from translocating to the nucleus and regulating gene transcription (29); when cells are stimulated by various endogenous, including DNA damage, ROS and lysosomal proteases, or exogenous factors, including interleukin (IL)-1, IL- 6 and tumor necrosis factor- $\alpha$, the NF- $\kappa$ B signaling pathway is activated and $\mathrm{I} \kappa \mathrm{B}$ will be phosphorylated and degraded, resulting in increased nuclear translocation of $\mathrm{P} 65$, which then binds to the promoter region of the corresponding gene to regulate its transcription and expression (30). The continuous activation of the NF- $\mathrm{NB}$ signaling pathway will result in the continuous expression of its target genes, which may result in an increased number of diseases, including cancer $(29,30)$. It has been reported that the $\mathrm{NF}-\kappa \mathrm{B}$ signaling pathway is involved in the regulation of VEGF-C expression (41). Previous studies reported that oxLDL can effectively promote the activation of $\mathrm{NF}-\kappa \mathrm{B}$ signaling pathway proteins $(27,28)$. The present data indicated that oxLDL promoted $\mathrm{I} \kappa \mathrm{B}$ and $\mathrm{P} 65$ phosphorylation to increase the degradation of $\mathrm{I} \kappa \mathrm{B}$. Subsequently, the nuclear translocation of P65 increased and the expression of VEGF-C was upregulated.

Additionally, VEGF-C is primarily expressed in and secreted from cancer tissues, and acts as a strong stimulator able to promote lymphangiogenesis and lymph node metastasis through binding to VEGF receptor-3 (42). It was demonstrated that oxLDL promotes VEGF-C expression and secretion in gastric cancer cells by activating the $\mathrm{NF}-\kappa \mathrm{B}$ signaling pathway through its receptor, LOX, and there was no evidence indicating that oxLDL can act on VEGF-C directly. It has been reported that LOX-1 can activate tumor-associated signaling pathways to promote the development of tumors (43). Simultaneously, it can maintain the growth of numerous tumors and is an important regulator of angiogenesis (42). This indicates that oxLDL may serve a role in the $\mathrm{NF}-\kappa \mathrm{B}$ signaling pathway through the mediation of LOX-1. The present results demonstrated the knockdown of LOX-1 on HGC-27 gastric cancer cells using interfering fragments and specific inhibitors can inhibit the aforementioned function of oxLDL to a certain extent. This indicates that LOX-1 mediates oxLDL activation of the NF- $\mathrm{B}$ signaling pathway and upregulation of VEGF-C. Combined with the aforementioned data, the present study may preliminarily outline the specific molecular mechanism by which oxLDL aggravates the lymph node metastasis of gastric cancer, providing a notable theoretical basis for the future prevention and treatment of gastric cancer lymphatic metastasis.

Li et al (44) demonstrated that ROS elimination could induce resistance to anoikis and promote nasopharyngeal carcinoma metastasis through blood vessels. As aforementioned, oxLDL or LOX-1 enhance ROS levels in cancer cells. The present data cannot exclude the possibility that oxLDL may promote the lymph node metastasis of gastric cancer cells by inducing resistance to anoikis, or even metastasis through blood vessels to lymphatic vessel. Considering that lymphatic is an important metastatic route of gastric cancer cells (19), it can be proposed that the lymph node metastasis enhancing mechanism of oxLDL is due to the upregulation of VEGF-C caused by activating the $\mathrm{NF}-\kappa \mathrm{B}$ signaling pathway. Furthermore, as a recent study elucidated, metastasis-initiating cells rely on dietary lipid uptake via cluster of differentiation 36 (CD36) to promote lymphatic metastasis (45). Hence, it is considered that if oxLDL/LOX-1 could interact with or regulate the expression or function of CD36, so far as to increase the quantity of metastasis-initiating cells, oxLDL will promote the lymph node metastasis of gastric cancer multi-dimensionally.

In conclusion, to the best of our knowledge, this was the first report that oxLDL promotes lymph node metastasis in gastric cancer, and to indicate the elucidated molecular mechanisms of oxLDL, including the upregulation of VEGF-C expression in and increased secretion from gastric cancer cells through 
the LOX-1/NF- $\mathrm{B}$ signaling pathway (Fig. 5E). These data support oxLDL elimination as a significant therapeutic target for the prevention and intervention of early lymph node metastasis in gastric cancer. However, whether oxLDL can be an independent marker for the early prediction of gastric cancer lymphatic metastasis remains to be determined. On account of our limited clinical data, a larger study population, further stratified and analyzed in terms of age, sex and BMI, should be used to resolve this problem in future studies.

An animal model of in situ induction would have been an improved choice for the present study. However, when the tracing of lymphatic metastatic gastric cancer cells was performed with an IVIS system, it was determined that it was difficult to distinguish the metastatic gastric cancer cells from the insitu ones. To solve this problem, a popliteal lymph node metastasis model was constructed that was successfully used in tracing the lymph node metastasis of cancer cells. BALB/C nude mice are a strain with a genetic mutation that causes the absence of a thymus, resulting in an inhibited immune system due to a notably reduced number of T cells. To avoid the negative influence of the inhibited immune system, an improved animal model such as a traceable orthotopic implantation model should be used to investigate this in future studies.

Lymphangiogenesis is a complicated process influenced with numerous factors, including VEGF-C, VEGF-D and VEGF-A, among others (42). In the preliminary experiment, the transcription levels of VEGF-C, VEGF-D and VEGF-A were detected in HGC-27 gastric cancer cells following treatment with oxLDL, and it was determined that VEGF-D and VEGF-A were upregulated, although only slightly. This indicates that the mechanism by which oxLDL regulates lymph node metastasis is complicated, and that it is worth further investigation in the future.

In summary, the present data preliminarily verified the correlation between oxLDL and lymph node metastasis of gastric cancer, and clarified the molecular mechanism of oxLDL promoting the lymph node metastasis in gastric cancer. These data indicate that oxLDL elimination could be a novel choice for the prevention and intervention of early lymph node metastasis in gastric cancer.

\section{Acknowledgements}

The authors would like to thank the assistance of Dr Wei Wang and Dr Wenjun Xiong from the Department of Gastrointestinal Surgery, Traditional Chinese Medicine Hospital of Guangdong Province (Guangzhou, China), and Dr Ting Zhang from the Guangzhou First People's Hospital (Guangzhou, China) for providing the clinical samples.

\section{Funding}

The present study was supported by the National Nature Science Foundation of China (grant nos. 81572342, 81770808, 81471033, 81600641, 81370945, 81400639, 81570871, 81570764, 81872165 and 81702879), the National Key Sci-Tech Special Project of China (grant nos. 2013ZX09102-053 and 2015GKS-355), the Key Project of Nature Science Foundation of Guangdong Province, China (grant nos. 2015A030311043, 2016A030311035 and 2016A020214001), the Guangdong Natural Science
Fund (grant nos. 2014A020212023, 2014A030313073, 2015A030313029 and 2015A030313103), the Guangdong Science Technology Project (grant no. 2017A020215075), the Initiate Research Funds for the Central Universities of China (Youth Program) (grant nos. 13ykpy06, 14ykpy05 and 16ykpy24), the Key Sci-tech Research Project of Guangzhou Municipality, China (grant nos. 201508020033, 201510010052, 201707010084 and 201803010017) the Pearl River Nova Program of Guangzhou Municipality, China (grant no. 201610010186) and the Fundamental Research Funds for the Central Universities (grant no. 2017BQ112).

\section{Availability of data and materials}

The datasets and materials used and/or analyzed during the current study are available from the corresponding author on reasonable request.

\section{Authors' contributions}

$\mathrm{XY}$ and GG designed the experiments and revised the manuscript. CM, JX and CL conducted the majority of the experiments and analyzed the data. CM and JX organized the figures and wrote the manuscript. HY, RL, XW, WX, TZha and PJ participated in the experiments. WQ, TZho, ZY, WW and JM participated in the experiments and revised the manuscript. All authors read and approved the final manuscript.

\section{Ethics approval and consent to participate}

All patient's provided written informed consent prior to surgery, and the use of medical records and biospecimens was approved by the Institutional Research Ethics Committee. All procedures relating to animal handling, experimentation and welfare were conducted in compliance with the Institutional Animal Care and Use Committee of Sun Yat-sen University (approval no. 20151011007).

\section{Patient consent for publication}

All of the patients recruited to the present study provided their consent for their data to be published in this paper.

\section{Competing interests}

The authors confirmed that they have no conflicts of interest.

\section{References}

1. Chen W, Zheng R, Baade PD, Zhang S, Zeng H, Bray F, Jemal A, $\mathrm{Yu}$ XQ and He J: Cancer statistics in China, 2015. CA Cancer J Clin 66: 115-132, 2016.

2. Torre LA, Siegel RL, Ward EM and Jemal A: Global cancer incidence and mortality rates and trends - an update. Cancer Epidemiol Biomarkers Prev 25: 16-27, 2016.

3. Van Cutsem E, Sagaert X, Topal B, Haustermans K and Prenen H: Gastric cancer. Lancet 388: 2654-2664, 2016.

4. Okholm C, Svendsen LB and Achiam MP: Status and prognosis of lymph node metastasis in patients with cardia cancer - a systematic review. Surg Oncol 23: 140-146, 2014.

5. Colquhoun A, Arnold M, Ferlay J, Goodman KJ, Forman D and Soerjomataram I: Global patterns of cardia and non-cardia gastric cancer incidence in 2012. Gut 64: 1881-1888, 2015. 
6. Witte MH, Bernas MJ, Martin CP and Witte CL: Lymphangiogenesis and lymphangiodysplasia: From molecular to clinical lymphology. Microse Res Tech 55: 122-145, 2001.

7. Calle EE, Rodriguez C, Walker-Thurmond $\mathrm{K}$ and Thun MJ: Overweight, obesity, and mortality from cancer in a prospectively studied cohort of U.S. adults. N Engl J Med 348: 1625-1638, 2003.

8. Tran GD, Sun XD, Abnet CC, Fan JH, Dawsey SM, Dong ZW, Mark SD, Qiao YL and Taylor PR: Prospective study of risk factors for esophageal and gastric cancers in the Linxian general population trial cohort in China. Int J Cancer 113: 456-463, 2005

9. De Pergola G and Silvestris F: Obesity as a major risk factor for cancer. J Obes 2013: 291546, 2013.

10. Han J, Jiang Y, Liu X, Meng Q, Xi Q, Zhuang Q, Han Y, Gao Y, Ding $\mathrm{Q}$ and Wu G: Dietary fat intake and risk of gastric cancer: A meta-analysis of observational studies. PLoS One 10: e0138580, 2015.

11. Sako A, Kitayama J, Kaisaki S and Nagawa H: Hyperlipidemia is a risk factor for lymphatic metastasis in superficial esophageal carcinoma. Cancer Lett 208: 43-49, 2004

12. Jung JI, Cho HJ, Jung YJ, Kwon SH, Her S, Choi SS, Shin SH, Lee KW and Park JH: High-fat diet-induced obesity increases lymphangiogenesis and lymph node metastasis in the B16F10 melanoma allograft model: Roles of adipocytes and M2-macrophages. Int J Cancer 136: 258-270, 2015.

13. Levitan I, Volkov S and Subbaiah PV: Oxidized LDL: Diversity, patterns of recognition, and pathophysiology. Antioxid Redox Signal 13: 39-75, 2010.

14. Chen KC, Liao YC, Wang JY, Lin YC, Chen CH and Juo SHH: Oxidized low-density lipoprotein is a common risk factor for cardiovascular diseases and gastroenterological cancers via epigenomical regulation of microRNA-210. Oncotarget 6: 24105-24118, 2015.

15. Delimaris I, Faviou E, Antonakos G, Stathopoulou E, Zachari A and Dionyssiou-Asteriou A: Oxidized LDL, serum oxidizability and serum lipid levels in patients with breast or ovarian cancer. Clin Biochem 40: 1129-1134, 2007.

16. Khaidakov M and Mehta JL: Do atherosclerosis and obesity-associated susceptibility to cancer share causative link to oxLDL and LOX-1? Cardiovasc Drugs Ther 25: 477-487, 2011.

17. Koskinen S, Enockson C, Lopes-Virella MF and Virella G: Preparation of a human standard for determination of the levels of antibodies to oxidatively modified low-density lipoproteins Clin Diagn Lab Immunol 5: 817-822, 1998.

18. Livak KJ and Schmittgen TD: Analysis of relative gene expression data using real-time quantitative PCR and the $2(-\Delta \Delta \mathrm{C}(\mathrm{T}))$ Method. Methods 25: 402-408, 2001.

19. Kitayama J, Hatano K, Kaisaki S, Suzuki H, Fujii S and Nagawa H: Hyperlipidaemia is positively correlated with lymph node metastasis in men with early gastric cancer. Br J Surg 91: 191-198, 2004

20. Skobe M, Hawighorst T, Jackson DG, Prevo R, Janes L, Velasco P, Riccardi L, Alitalo K, Claffey K and Detmar M: Induction of tumor lymphangiogenesis by VEGF-C promotes breast cancer metastasis. Nat Med 7: 192-198, 2001

21. Swartz MA and Skobe M: Lymphatic function, lymphangiogenesis, and cancer metastasis. Microsc Res Tech 55: 92-99, 2001.

22. Pereira ER, Jones D, Jung K and Padera TP: The lymph node microenvironment and its role in the progression of metastatic cancer. Semin Cell Dev Biol 38: 98-105, 2015.

23. Mumprecht V, Honer M, Vigl B, Proulx ST, Trachsel E, Kaspar M, Banziger-Tobler NE, Schibli R, Neri D and Detmar M: In vivo imaging of inflammation- and tumor-induced lymph node lymphangiogenesis by immuno-positron emission tomography. Cancer Res 70: 8842-8851, 2010.

24. Ma C, Luo C, Yin H, Zhang Y, Xiong W, Zhang T, Gao T, Wang X, Che D, Fang Z, et al: Kallistatin inhibits lymphangiogenesis and lymphatic metastasis of gastric cancer by downregulating VEGF-C expression and secretion. Gastric Cancer 21: 617-631, 2018

25. Mäkinen T, Veikkola T, Mustjoki S, Karpanen T, Catimel B, Nice EC, Wise L, Mercer A, Kowalski H, Kerjaschki D, et al: Isolated lymphatic endothelial cells transduce growth, survival and migratory signals via the VEGF-C/D receptor VEGFR-3. EMBO J 20: 4762-4773, 2001

26. Zhu G, Huang Q, Huang Y, Zheng W, Hua J, Yang S, Zhuang J, Wang $\mathrm{J}$ and Ye J: Lipopolysaccharide increases the release of VEGF-C that enhances cell motility and promotes lymphangiogenesis and lymphatic metastasis through the TLR4- NF- $\mathrm{KB} / \mathrm{JNK}$ pathways in colorectal cancer. Oncotarget 7: 73711-73724, 2016.
27. Nishimura S, Akagi M, Yoshida K, Hayakawa S, Sawamura T, Munakata $\mathrm{H}$ and Hamanishi C: Oxidized low-density lipoprotein (ox-LDL) binding to lectin-like ox-LDL receptor-1 (LOX-1) in cultured bovine articular chondrocytes increases production of intracellular reactive oxygen species (ROS) resulting in the activation of NF-kappaB. Osteoarthritis Cartilage 12: 568-576, 2004.

28. Li S, Guo Y, Zhu P and Yang T: Role of Ox-LDL/LOX-1/NF-кB signaling pathway in regulation of atherosclerotic plaque growth by testosterone in male rabbits. Vascul Pharmacol 59: 131-137, 2013.

29. Ray A and Prefontaine KE: Physical association and functional antagonism between the p65 subunit of transcription factor NF-kappa B and the glucocorticoid receptor. Proc Natl Acad Sci USA 91: 752-756, 1994.

30. Christian F, Smith EL and Carmody RJ: The regulation of NF- $\kappa B$ subunits by phosphorylation. Cells 5: 5, 2016.

31. Lu J, Mitra S, Wang X, Khaidakov M and Mehta JL: Oxidative stress and lectin-like ox-LDL-receptor LOX-1 in atherogenesis and tumorigenesis. Antioxid Redox Signal 15: 2301-2333, 2011.

32. Akhmedov A, Rozenberg I, Paneni F, Camici GG, Shi Y, Doerries C, Sledzinska A, Mocharla P, Breitenstein A, Lohmann C, et al: Endothelial overexpression of LOX-1 increases plaque formation and promotes atherosclerosis in vivo. Eur Heart J 35: 2839-2848, 2014

33. Falconi M, Ciccone S, D'Arrigo P, Viani F, Sorge R, Novelli G, Patrizi P, Desideri A and Biocca S: Design of a novel LOX-1 receptor antagonist mimicking the natural substrate. Biochem Biophys Res Commun 438: 340-345, 2013.

34. Beasley NJ, Prevo R, Banerji S, Leek RD, Moore J, van Trappen P, Cox G, Harris AL and Jackson DG: Intratumoral lymphangiogenesis and lymph node metastasis in head and neck cancer. Cancer Res 62: 1315-1320, 2002.

35. Coşkun U, Akyürek N, Dursun A and Yamaç D: Peritumoral lymphatic microvessel density associated with tumor progression and poor prognosis in gastric carcinoma. J Surg Res 164: 110-115, 2010.

36. Alitalo K and Carmeliet P: Molecular mechanisms of lymphangiogenesis in health and disease. Cancer Cell 1: 219-227, 2002.

37. Su JL, Yang PC, Shih JY, Yang CY, Wei LH, Hsieh CY, Chou CH, Jeng YM, Wang MY, Chang KJ, et al: The VEGF-C/Flt-4 axis promotes invasion and metastasis of cancer cells. Cancer Cell 9: 209-223, 2006

38. Zettler ME, Prociuk MA, Austria JA, Massaeli H, Zhong G and Pierce GN: OxLDL stimulates cell proliferation through a general induction of cell cycle proteins. Am J Physiol Heart Circ Physiol 284: H644-H653, 2003.

39. Cheng R and Ma JX: Angiogenesis in diabetes and obesity. Rev Endocr Metab Disord 16: 67-75, 2015

40. Gao G, Li Y, Zhang D, Gee S, Crosson C and Ma J: Unbalanced expression of VEGF and PEDF in ischemia-induced retinal neovascularization. FEBS Lett 489: 270-276, 2001.

41. Tsai PW, Shiah SG, Lin MT, Wu CW and Kuo ML: Up-regulation of vascular endothelial growth factor $\mathrm{C}$ in breast cancer cells by heregulin-beta 1 . A critical role of p38/nuclear factor-kappa B signaling pathway. J Biol Chem 278: 5750-5759, 2003.

42. Stacker SA, Williams SP, Karnezis T, Shayan R, Fox SB and Achen MG: Lymphangiogenesis and lymphatic vessel remodelling in cancer. Nat Rev Cancer 14: 159-172, 2014.

43. Li C, Zhang J, Wu H, Li L, Yang C, Song S, Peng P, Shao M, Zhang M, Zhao J, et al: Lectin-like oxidized low-density lipoprotein receptor-1 facilitates metastasis of gastric cancer through driving epithelial-mesenchymal transition and PI3K/Akt/GSK3 beta activation. Sci Rep 7: 45275, 2017.

44. Li S, Mao Y, Zhou T, Luo C, Xie J, Qi W, Yang Z, Ma J, Gao G and Yang $\mathrm{X}$ : Manganese superoxide dismutase mediates anoikis resistance and tumor metastasis in nasopharyngeal carcinoma. Oncotarget 7: 32408-32420, 2016

45. Pascual G, Avgustinova A, Mejetta S, Martín M, Castellanos A, Attolini CS, Berenguer A, Prats N, Toll A, Hueto JA, et al: Targeting metastasis-initiating cells through the fatty acid receptor CD36. Nature 541: 41-45, 2017.

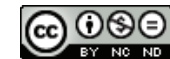

This work is licensed under a Creative Commons Attribution-NonCommercial-NoDerivatives 4.0 International (CC BY-NC-ND 4.0) License. 